Int. J. Dev. Biol. 53: 597-603 (2009)

doi: $10.1387 / \mathrm{ijdb} .082648 \mathrm{vz}$

\title{
Generation and functional characterization of mice with a conditional BMP7 allele
}

\author{
VASILIKI ZOUVELOU ${ }^{1}$, OURANIA PASSA ${ }^{1}$, KATERINA SEGKLIA ${ }^{1}$, SOTIRIS TSALAVOS ${ }^{1}$, \\ DAVID M. VALENZUELA2 ${ }^{2}$, ARIS N. ECONOMIDES ${ }^{2}$ and DANIEL GRAF*,1,3 \\ ${ }^{1}$ Institute of Immunology, Biomedical Sciences Research Center 'Al. Fleming', Hellas/Greece and \\ ${ }^{2}$ Genome Engineering Technologies, Regeneron Pharmaceuticals, Tarrytown, NY, USA
}

\begin{abstract}
Bone Morphogenetic Proteins (BMPs) play multiple and important roles in embryonic development as well as in homeostasis and tissue repair in the adult. Bmp7 has been implicated in developmental disorders and in a variety of diseases, but functional studies to elucidate its role so far have been hampered, since mice deficient in BMP7 die around or just after birth. To facilitate such studies, we generated mice in which the $B m p 7$ gene has been rendered conditional-null by flanking its first coding exon with loxP sites. To this end, we adapted the two-loxP site strategy to Bacterial Homologous Recombination to create a Bacterial Artificial Chromosome-based vector for direct targeting in mouse embryonic stem cells. Functional analysis showed that in vivo, the conditional-null $B m p f^{f|x / f| x}$ mice are phenotypically wild type, whereas post Cre-mediated recombination, the resulting $B m p 7^{\Delta / \Delta}$ mice are phenotypically null. Thus, this study validates the usefulness of the $B m p f^{f|x / f| x}$ mouse which in turn should empower in vivo studies aimed at elucidating the roles of $B m p 7$ in postnatal development, homeostasis and disease.
\end{abstract}

KEY WORDS: bone morphogenetic protein, gene targeting, Cre-LoxP, bacterial homologous recombination

\section{Introduction}

BMPs are evolutionary conserved, secreted signaling molecules belonging to the TGF- $\beta$ superfamily. Contrary to what is suggested by their name their function is not restricted to bone. BMPs have multiple roles during embryogenesis where they are involved in early embryonic pattering, gastrulation, tissue induction and differentiation. In addition, BMPs have been shown to be involved in homeostasis and repair of several adult tissues (Sancho et al., 2004, Lories and Luyten, 2005, Simic and Vukicevic, 2005), and several Bmps including BMP7 are used in the clinic for orthopaedic and bone healing applications.

BMP7 is the orthologue of Drosophila glass bottom boat ( $\mathrm{Gbb}$ / $60 A$ ) and is most closely related to BMP5 and BMP6. BMP7deficient mice in their majority die soon after birth. They present multiple defects, most prominently in lens induction, kidney development, and skeletal patterning where defects are restricted to the rib cage, the skull, and the hindlimbs (Dudley et al., 1995, Luo et al., 1995, Jena et al., 1997). Although BMP7 has been implicated to play a role in the homeostasis and repair of several adult tissues such as the kidney, liver, and central nervous system
(Patel and Dressler, 2005, Zeisberg et al., 2007, Ara et al., 2008), and although it is used in clinical settings, surprisingly little is known about its roles in adult tissues in vivo. For example, Bmp7 is expressed in thymic stroma as well as a variety of cell types of the immune system (Graf et al., 2002 and unpublished observations). Therefore, in order to empower studies on the function of BMP7 in the immune system and other adult tissues in vivo, a conditional-null allele for Bmp7 was generated.

\section{Results and Discussion}

In the mouse, Bmp7 is located towards the distal end of chromosome 2. It contains 7 exons spanning about $73 \mathrm{~kb}$ (Fig. $1 \mathrm{~A})$, and it lies in a relative isolation from other genes. The closest neighbor is Spo11 approximately $40 \mathrm{~kb}$ upstream of $B m p 7$ exon 1 and is transcribed into the opposite direction. Full-length tran-

Abbreviations used in this paper: BAC, bacterial artificial chromosome; BMP, bone morphogenetic protein; ECR, evolutionary conserved region; ES, embryonic stem; H/E, hematoxylin/eosin; TGF $\beta$, tumor growth factor.

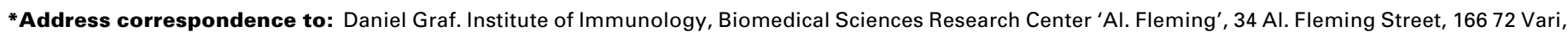
Hellas/Greece. e-mail: graf@fleming.gr
}

Supplementary Material (MP4 podcast) for this paper is available at: http://dx.doi.org/10.1387/ijdb.082648vz

Accepted: 11 December 2008. Published online: 26 February 2009.

ISSN: Online 1696-3547, Print 0214-6282

(C) 2009 UBC Press

Printed in Spain 


\section{A BMP7 genomic locus}

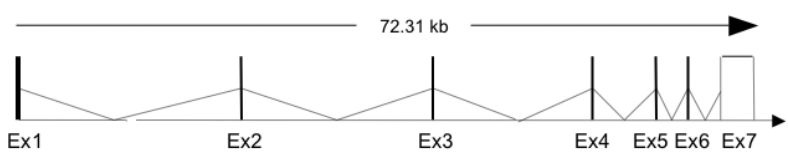

\section{B Targeting Vector}

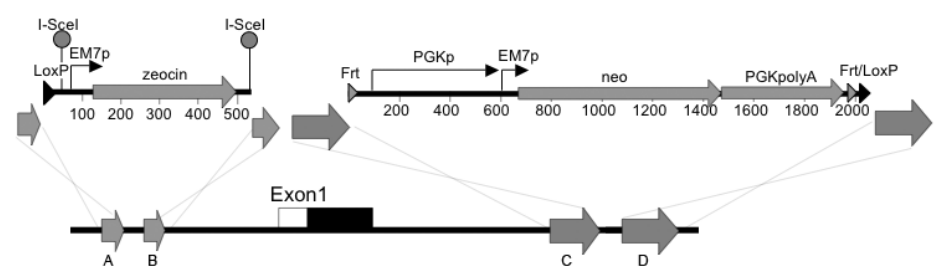

\section{Targeted Allele}

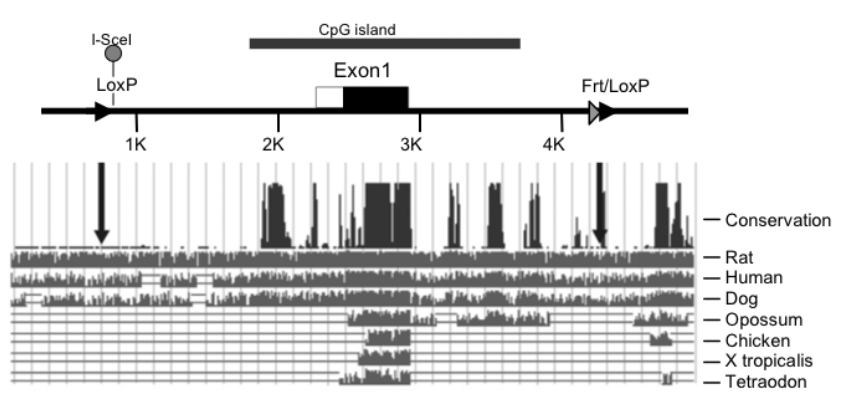

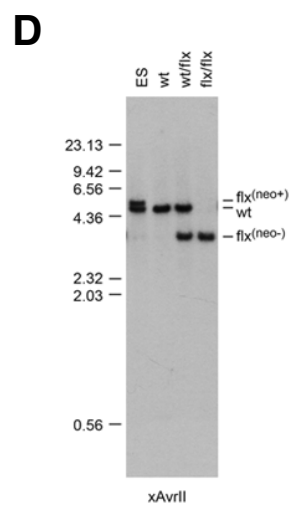

Fig. 1. Targeting strategy generating a conditional-null allele of Bmp7. (A) Schematic representation of the mouse $\mathrm{Bmp} 7$ locus indicating the relative location of the exons 1-7, adapted from http://ensembl.org. (B) Schematic representation of the targeting strategy and generic cassettes used. Both generic modification cassettes used for $5^{\prime}$ and $3^{\prime}$ targeting were flanked with appropriate homology boxes (labeled $A-D$ ) to allow for recombination to occur. Both modification cassettes were engineered to allow for excision of selection cassettes. (C) Location of targeting elements flanking exon 1 after removal of selection cassettes (Bmp $7^{f(x)}$ in relation to evolutionary conserved region (ECR), adapted from http://genome.ucsc.edu. Degree of conservation is indicated. LoxP integration sites are indicated and were chosen as not to disrupt ECRs. (D) Southern Blot with DNA isolated from targeted ES cells (lane 1) or tail biopsies from Bmp7 ${ }^{\mathrm{wt}}, \mathrm{Bmp} 7^{\mathrm{wt} / \mathrm{fl} \times \mathrm{B}}, \mathrm{Bmp} 7^{\mathrm{fl} \times \mathrm{ff|x}}$ mice confirming correct targeting (lanes 2, 3, and 4). The genotyping strategy used is described in Fig. $2 \mathrm{~A}$.

scripts of Bmp7 as detected by Northern Blot (Ozkaynak et al., 1992) are $4 \mathrm{~kb}$ and $2.2 \mathrm{~kb}$ respectively. The $1.9 \mathrm{~kb}$ open-reading frame encodes a deduced protein of 440 amino acids. BMP7 is expressed in an inactive pro-form and proteolytic cleavage by Furin proteases is required to release the 139-amino acid mature peptide (Jones et al., 1994). For the generation of Bmp7 null alleles by gene targeting in ES cells different strategies have been used. Dudley et al., 1995 removed the first exon encoding the signal peptide as well as a large part of the preBMP7 peptide. Luo et al., 1995 removed exons 6 and 7 , which together encode most of the mature protein, where as Jena et al., 1997 inadvertedly removed part of exon 3 in the process of making transgenic lines for Bcl2. All three Bmp7 knockout alleles show very similar phenotypes in homozygosis, though some differences have been noted, particularly with respect to penetrance of the kidney phenotype and the skeletal malformations. Still, since in all three alleles no $B m p 7$ message could be detected, these differences are most likely due to genetic background rather than being reflective of differences in allele design.

To engineer a conditional-null allele we chose to flank the first coding exon (exon 1) of Bmp7 with loxP sites (Fig. 1B). Cre-mediated recombination would remove exon 1 that contains the signal peptide and a large part of preBMP7, mirroring the strategy used by Dudley et al., 1995. By removing the first coding exon we not only would create a $B m p 7$ null allele but we also exclude the chance of expressing the aminoterminal pre-protein, which theoretically may interfere with the processing and maturation of other BMPs. Comparative sequence analysis of the $B m p 7$ locus revealed the presence of several evolutionarily conserved regions (ECRs) including a well-conserved CpG island stretching either side of exon 1 (Fig. 1C). Care was taken not to place the loxP sites into ECRs or the $\mathrm{CpG}$ island in order to avoid disrupting potential regulatory elements, an event that could result in alteration of expression of either $B m p 7$ or other nearby genes (Graf and Economides, 2008). Incidentally, it was recently shown that the majority of regulatory elements required for $B m p 7$ expression in kidney, eye, and hindlimb are located in ECRs contained within $20 \mathrm{~kb}$ surrounding exon 1 (Adams et al., 2007). In addition, neighboring genes were also taken into consideration. The closest neighbor is Spo11 lying approximately $40 \mathrm{~kb}$ upstream of Bmp7 exon 1. As the 5' loxP site was located only $1,66 \mathrm{~kb}$ upstream of exon 1 , we considered it rather unlikely that insertion of the 5' loxP site could affect expression of Spo11.

For the generation of the targeting vector we adapted the standard two-loxP site strategy for generating conditional alleles to VelociGene ${ }^{\circledR}$, a process which couples the use of BACs as targeting vectors with $\mathrm{QPCR}$-based genotyping screen for targeted ES clones (Valenzuela et al., 2003). The targeting vector was assembled on the BAC by two rounds of Bacterial Homologous Recombination (Muyrers et al., 1999) using generic modification cassettes shown in Fig. 1B. The modification cassette for the 5 ' loxP site consisted of a loxP site followed by Zeocin selection cassette flanked by I-Scel sites that allows its removal by digestion and re-ligation of the modified BAC in vitro. The modification cassette for the 3' loxP site consisted of a loxP site followed by an Frt flanked combined Kanamycin/ Neomycin selection (Neo) cassette. Both modification cassettes were flanked with appropriate homology regions for Bacterial Homologous Recombination and introduced into the BAC. After removal of the Zeocin cassette the modified BAC was linearized and then used directly as the targeting vector. Targeted ES cells were identified by a loss of allele assay (not shown) (Valenzuela et al., 2003). In addition, Southern blot analysis on ES cell derived 
DNA confirmed correct targeting of the Bmp7 allele as the ratio of targeted to wt allele was 1:1 (Fig. 1D, lane 1). Chimaeric mice were generated by injection of targeted ES cells into blastocysts, and the allele was passed through the germline. The Bmp $f^{f x(N e o) /}$ ${ }^{+}$mice were crossed to a germline Flp-deleter mouse (Farley et al., 2000) to remove the Neo cassette. Removal of the Neo cassette was confirmed by Southern blot (Fig. 1D, lane 3) and sequencing of the PCR products obtained from typing of genomic DNA (not shown). Fig. $1 \mathrm{C}$ shows a representation of the final targeted $B m p f^{f l x(n e o-)}$ allele, which is subsequently referred to as $B m p 7^{f l x}$, indicating the placement of the loxP sites outside of evolutionary conserved regions. Subsequent intercrosses of $B m p 7^{w t / f l x}$ mice resulted in $B m p 7^{f \mid x / f l x}$ mice in the expected Mendelian ratio confirming targeting of the endogenous Bmp7gene. Examples of resulting genotypes are shown in Fig. 1D lanes 2-4. Details on the typing strategy are given in Fig. 2A. Bmpfflx/flx appeared healthy and bred normally, and were in all respects physiologically indistinguishable from their wild type littermates. In particular, no differences in fertility were observed indicating that the introduction of the 5' loxP site did not affect the nearby Spo11 gene locus.

To test the ability of the allele to efficiently recombine in vivo in a tissue specific manner we crossed the $B m p 7^{f l x}$ allele to the Vav-Cre mouse. The Vav-Cre mouse deletes in all hematopoietic cells (de Boer et al., 2003) that can conveniently be isolated from lymphoid tissues to assess efficiency of deletion. Hematopoietic cells as identified by the expression of CD45 routinely make up $>96 \%$ of the cells isolated from a mechanically disrupted thymus or $>97 \%$ of nucleated cells from the bone marrow. A representation of the various $B m p 7$ alleles and details of the respective typing strategies are given in Fig. 2A. Southern Blot analysis failed to detect a $B m p f^{f l x}$ allele in Vav-Cre:Bmp $7^{f(x / f l x}$ thymocytes and Bone Marrow cells (Fig. 2B) indicating efficient deletion of the flx allele. PCR typing on the thymocyte derived genomic DNA using a 4-primer strategy to simultaneously identify $B m p 7^{w t}, B m p 7^{f l x}$, and $B m p 7^{\Delta}$ alleles in a single PCR sample confirmed the Southern blot re-

Fig. 2. Details on design, assembly, and typing of Bmp7 conditional-null allele. (A) Schematic to scale representations of $w t, f / x^{(n e o+)}, f / x^{(n e o-)}$, and $\Delta$ alleles indicating coding elements, homology boxes (labeled A-D), restriction sites and primers used. Expected fragment sizes for Southern typing are indicated above the respective diagrams. Primer combinations for PCR typing are: D151/D152 for wt allele, D151/D153 for fl $x^{\text {(neo+) }}$ allele, D151/D154 for $\mathrm{fl}^{\text {(neo-) }^{(1)} \text { allele, }}$ and D151/D155 for the $\Delta$ allele. The D151/D152 fragment was used as probe for Southern blot typings described below. (B,C) Efficient deletion in vivo of the conditional allele in Vav-Cre:Bmp7 $7^{\mathrm{fl} x f \mathrm{~lx}}$ cells. Southern blot using $\mathrm{Xbal}$ and probe D151/D152 on DNA obtained from thymocytes and Bone Marrow cells (B) and PCR typing using the 4-primer strategy on DNA from thymocytes (C). No residual $\mathrm{Bmp} 7^{\mathrm{flx}}$ signal could be detected in Vav-Cre:Bmp $7^{\mathrm{fl} \times \mathrm{fl|}}$ cells indicating efficient recombination in vivo.

A sults (Fig. 2C).

To assess whether the $B m p 7^{\Delta}$ allele phenotypically matches the previously engineered null alleles (Dudley et al., 1995, Luo et al., 1995, Jena et al., 1997), Bmp $7^{f l x /+}$ mice were crossed to a germline deleting Cre mouse (Schwenk et al., 1995) to obtain $B m p 7^{\Delta /+}$ mice. The deletion was passed germline and the Creallele was removed. Deletion of the floxed region and conversion of the $B m p 7^{f l x}$ allele to $B m p 7^{\Delta}$ was confirmed by Southern blot (Fig. 3A) and PCR typing (not shown). Sequencing of the PCR product obtained from DNA typing confirmed that Cre-mediated deletion resulted in loss of exon1 mirroring the targeting strategy
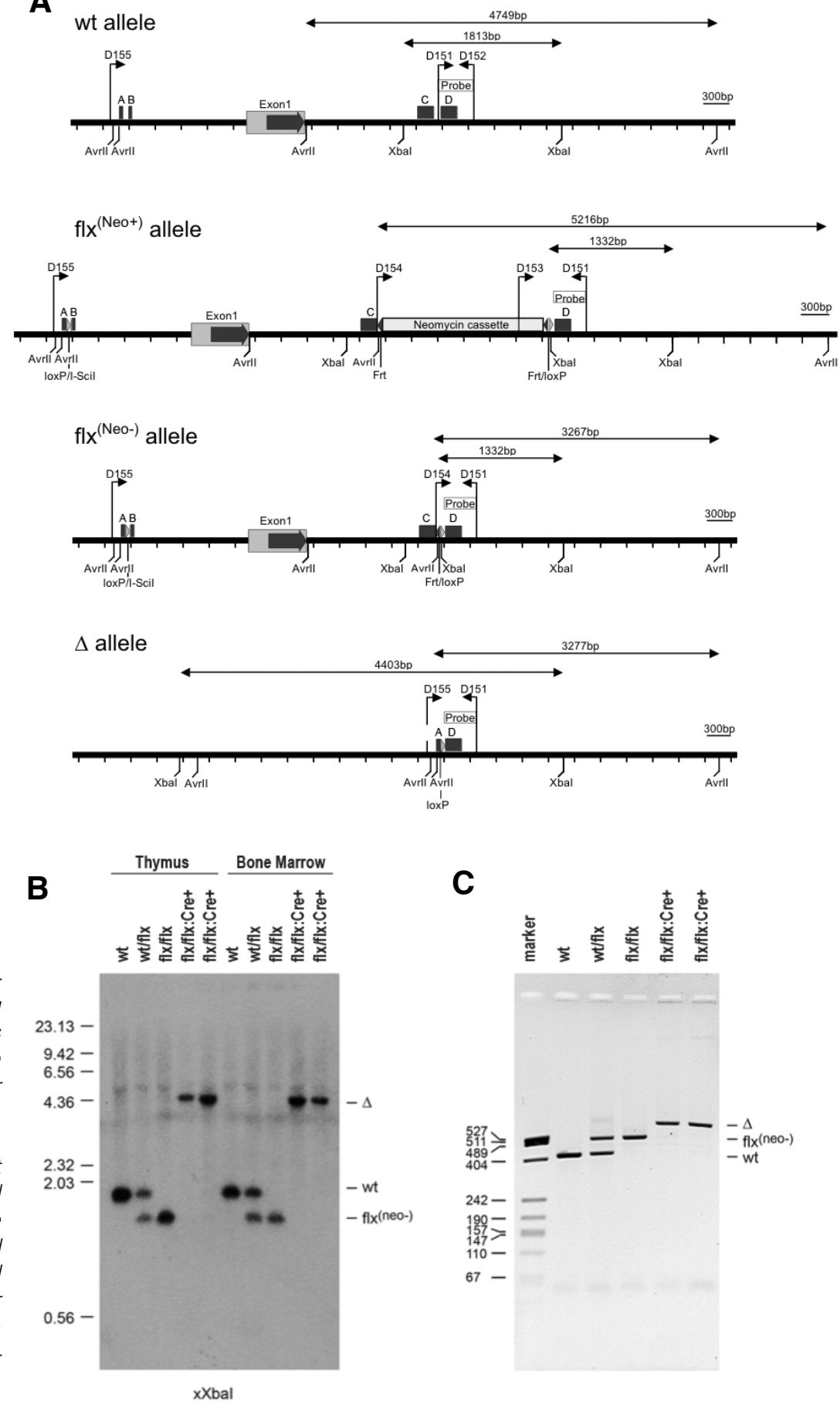


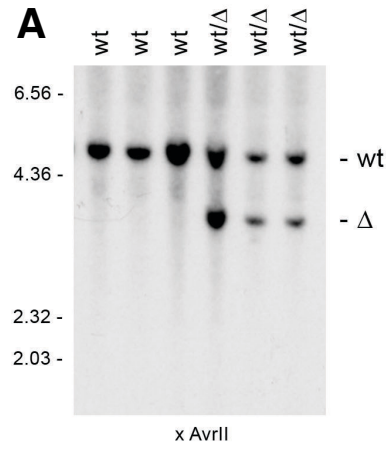

C -
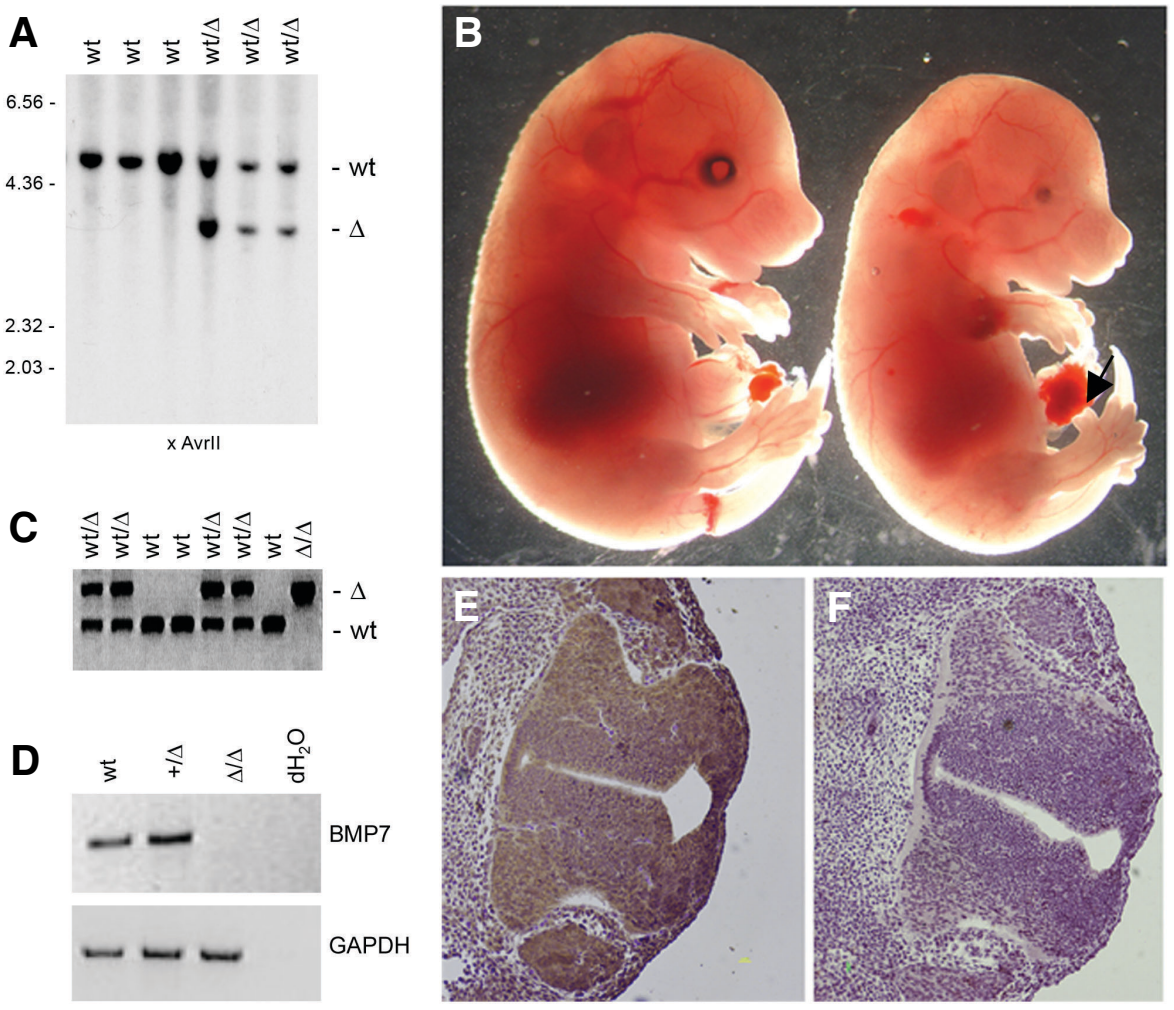

Fig. 3. Loss of Bmp7 expression in $B m p 7^{\Delta / \Delta}$ embryos. (A) Southern blot confirming the Bmp7wt/s genotype. Bmp7wt/s mice were intercrossed to generate $B \mathrm{mp} 7^{\mathrm{\Delta} / \Delta}$ embryos. (B) E15.5 Bmp7wt (right) and $\mathrm{Bmp} 7^{\Delta / \Delta}$ (left) embryo showing reduction in size, anophtalmia, and polydactyly on hind limb (black arrow) (C) PCR-typing of genomic DNA to confirm presence of $B m p 7^{\Delta / \Delta}$ embryos. (D-F) Loss of $\mathrm{Bmp} 7$ expression in $\mathrm{Bmp} 7^{\Delta / \Delta}$ embryos using $R T$ $P C R$ on embryonic RNA (D) and immunohistochemistry on of $E 16.5 \mathrm{Bmp} 7 \mathrm{wt} / \mathrm{wt}(\mathbf{E})$ and $B \mathrm{Bmp} 7^{\Delta / \Delta}(\mathbf{F})$ sections. Loss of Bmp7 expression in neurepithelium of the spinal cord and the somites can be observed.
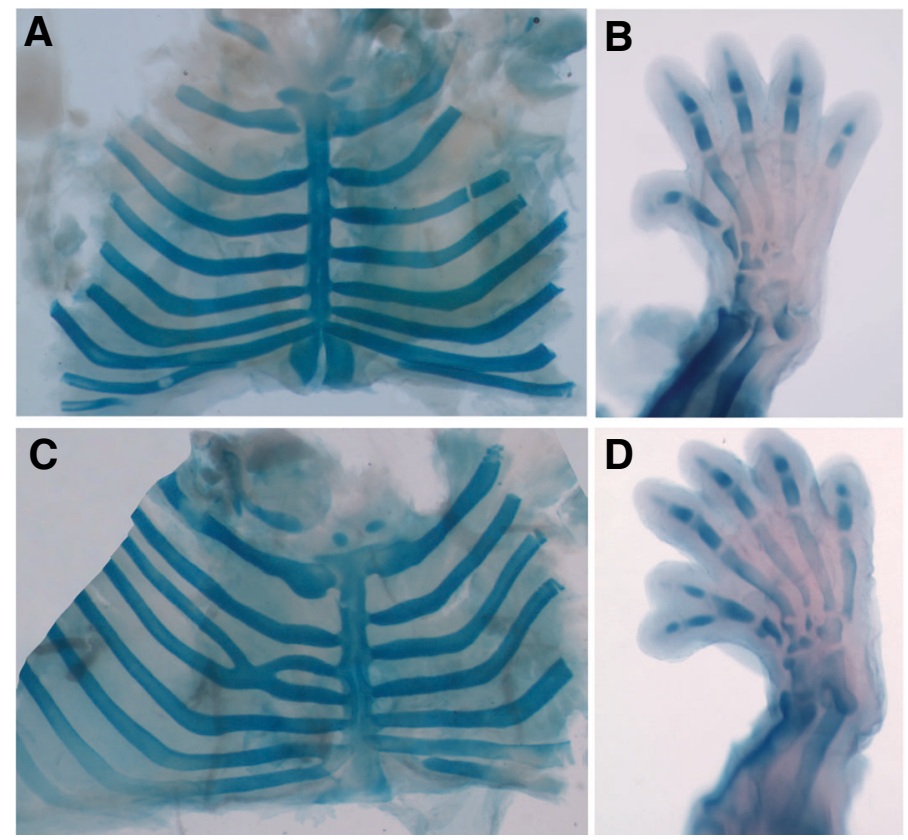

Fig. 4 (Left). Skeletal malformation in $B m p 7^{\Delta \Delta \Delta}$ embryos. Alcian blue stained skeletal preparations of E16.5 $\mathrm{Bmp} 7 \mathrm{wt} / \mathrm{wt}$ embryo $(\mathbf{A}, \mathbf{B})$ and $\mathrm{Bmp}^{\mathrm{\Delta} / \Delta}$ embryo (C,D). (A) Ventral view of the rib cage of Bmp7wt/wt embryo. (B) Dorsal view of the right pes of Bmp7wt/wt embryo. (C) Ventral
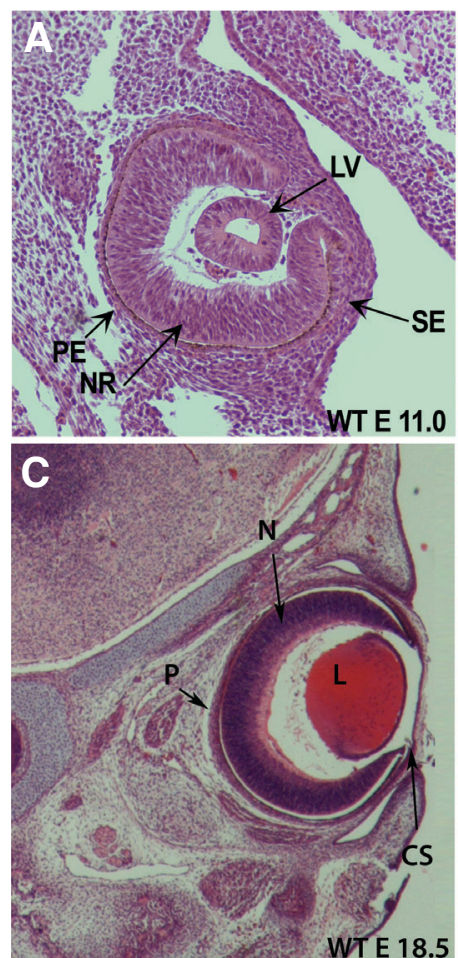
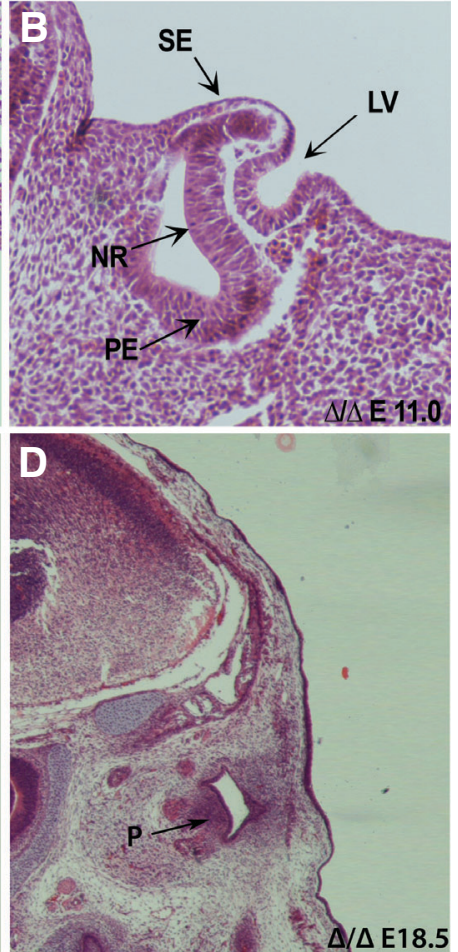

view of the rib cage of Bmp7 ${ }^{\Delta / \Delta}$ embryo showing multiply defects, such as fusion of the third and forth left ribs, bifurcation of the sixth and seventh left ribs and deformed sternum with asymmetrical alignment of the ribs. (D) Dorsal view of the right pes of Bmp7 ${ }^{\Delta / \Delta}$ embryo with an extra ungula phalanx.

Fig. 5 (Right). Eye phenotype in Bmp $7^{\Delta / \Delta}$ embryos. Sagital sections of Bmp7wt/wt (A) and Bmp $7^{\Delta / \Delta}$ (B) E11.0 embryos stained with Hematoxylin/ Eosin. Note that $L V$ is not completely closed whereas $S E, P E$, and NR are present. Coronal section of Bmp $7^{\text {wt/wt }}$ (C) and Bmp7 $7^{\Delta / \Delta}$ (D) E18.5 embryos showing defective eye development with disorganized remnants of pigmented epithelial cells. OV, optic vesicle; OS, optic stalk; $L V$, lens vesicle; SE, surface ectoderm; PE, pigmented epithelium; NR, neural retina; $P$, pigmented epithelial cells; $L$, lens; $N$, neural layer of retina; SC, conjunctival sac. 
TABLE 1

\section{EMBRYOS WERE RECOVERED BETWEEN E11.5 AND E18.5 AND TYPED BY PCR}

\begin{tabular}{llccccc} 
Litters & Embryos & $\begin{array}{c}\Delta / \Delta \text { Mutants } \\
(\%)\end{array}$ & $\begin{array}{c}\text { Kidney } \\
\text { defects (\%) }\end{array}$ & $\begin{array}{c}\text { Eye defects } \\
(\%)\end{array}$ & $\begin{array}{c}\text { Polydactyly } \\
(\%)\end{array}$ & $\begin{array}{c}\text { Rib Cage } \\
\text { defects (\%) }\end{array}$ \\
\hline 13 & 75 & $15(20)$ & $15(100)$ & $15(100)$ & $11(73.3)$ & $10(66.6)$ \\
\hline
\end{tabular}

The eye defects of the $B m p 7$ null embryos ranged from microphthalmia to complete anophthalmia, whereas the rib cage defects ranged from failure of one or two of the seventh pair of ribs to fuse with the sternum, fused ribs, bifurcated ribs, and deformed sternum.

used by Dudley et al. (1995) (not shown). Subsequent intercrosses of $B m p 7^{\Delta /+}$ mice did not yield viable $B m p 7^{\Delta / \Delta}$ offspring.

To analyze the phenotype of $B m p 7^{\Delta / \Delta}$ mice, embryos were recovered at e15.5-e17.5, stages at which the published $B m p 7-$ null defects are clearly established (Dudley et al., 1995, Luo et al., 1995). Bmp $7^{\Delta / \Delta}$ offspring could faithfully be recognized by the eye-phenotype (Fig. 3B). PCR typing was used for confirmation and to identify $B m p 7^{w t}$ and $B m p 7^{w t / \Delta}$ embryos (Fig. $3 C$ ). RT-PCR analysis and immunohistochemistry confirmed the absence of Bmp7 mRNA and protein in embryonic tissues (Fig. $3 \mathrm{D}, \mathrm{E})$. As shown in Fig. 3B, macroscopic inspection of Bmp7 ${ }^{\Delta /}$ ${ }^{\Delta}$ embryos revealed a shorter $\mathrm{A} / \mathrm{P}$ axis and fully penetrant anophtalmia or microopthalmia. Several skeletal malformations with variable penetrance were also recorded such as polydactily of the hindlimbs (Figs. 3B,4). Skeletal preparations revealed further occasional presence of fused ribs, bifurcated ribs, and deformed sternum (Fig. 4). All these macroscopic phenotypic alterations are in line with previous reports (Dudley et al., 1995, Luo et al., 1995).

More detailed histological analysis of the eye phenotype at various developmental stages (Fig. 5) revealed malformations comparable to those previously reported (Dudley et al., 1995). For example, induction of the lens placode and invagination of the lens vesicle occured in $B m p 7^{\Delta / \Delta}$ embryos, and at e9.5 the optic vesicle and the optic stalk were clearly present (not shown). By e11.0 there was a delay in the development of the lens vesicle of the $B m p 7^{\Delta / \Delta}$ mice, showing incomplete closure (Fig. $5 \mathrm{~A}, \mathrm{~B}$ ), whereas structures such as the surface ectoderm, the pigmented epithelium, and the neural retina appeared normal. However, at subsequent developmental stages the eye structures of the mutant embryos showed a profound deterioration and by e18.5 only a few disorganized pigmented epithelial cells remained at the site where the eye should have been. As Bmp7 is expressed in various regions in and around the developing eye (Zouvelou et al., 2009), the fully-penetrant eye phenotype is a likely a reflection of multiple requirements for $B m p 7$ for development and maintenance of the eye structure.

The kidneys of $B m p 7^{\Delta / \Delta}$ embryos were hypoplastic, and histological analysis revealed reduced development of the glomeruli structures similar to what was reported by Dudley et al., 1995 (Fig. 6 A,B). In most cases the glomeruli had dilated bowman's capsules (Fig 6 C,D). Around the uteric buds the interstitital mesenchyme was loose with an apparent loss of orientation. There was also a strong reduction in comma shaped bodies. (Fig. 6 E,F). In Table 1, the degrees of penetrance of above phenotypes are indicated showing comparable values to the published ones.

This limited analysis confirmed that Cre-mediated deletion of exon1 recapitulates the $B m p 7$ null allele generated by Dudley et al., 1995. Excision of the floxed exon by Cre lines appears efficient, and at least in the case of general deletion, the resulting $B m p 7^{\Delta / \Delta}$ mice phenocopy the published null lines, thus establishing the functionality and usefulness of this $B m p 7$ conditional-null allele. It should be noted that additional phenotypic changes were observed in $B m p 7^{\Delta / \Delta}$ embryos and that these changes coincided nicely with sites of Bmp7 expression (Zouvelou et al., 2009). It is not clear whether these additional phenotypes were simply not described in the original publications or whether they are due to the genetic background. In support of the latter possibility, and simultaneously ruling out attribution to differences in allele design, Bmp7lacZ/lacZ (Godin et al., 1998) on a C57BI/6 background displayed comparable additional phenotypes (data not shown).

In summary, we describe a method to generate conditional-null alleles by Bacterial Homologus Recombination, and use Bmp7 as an example. This $B m p 7^{f l x}$ allele recombines efficiently in vivo and acts as a null allele after recombination. The availability of this allele should be a valuable tool for studies directed at deciphering
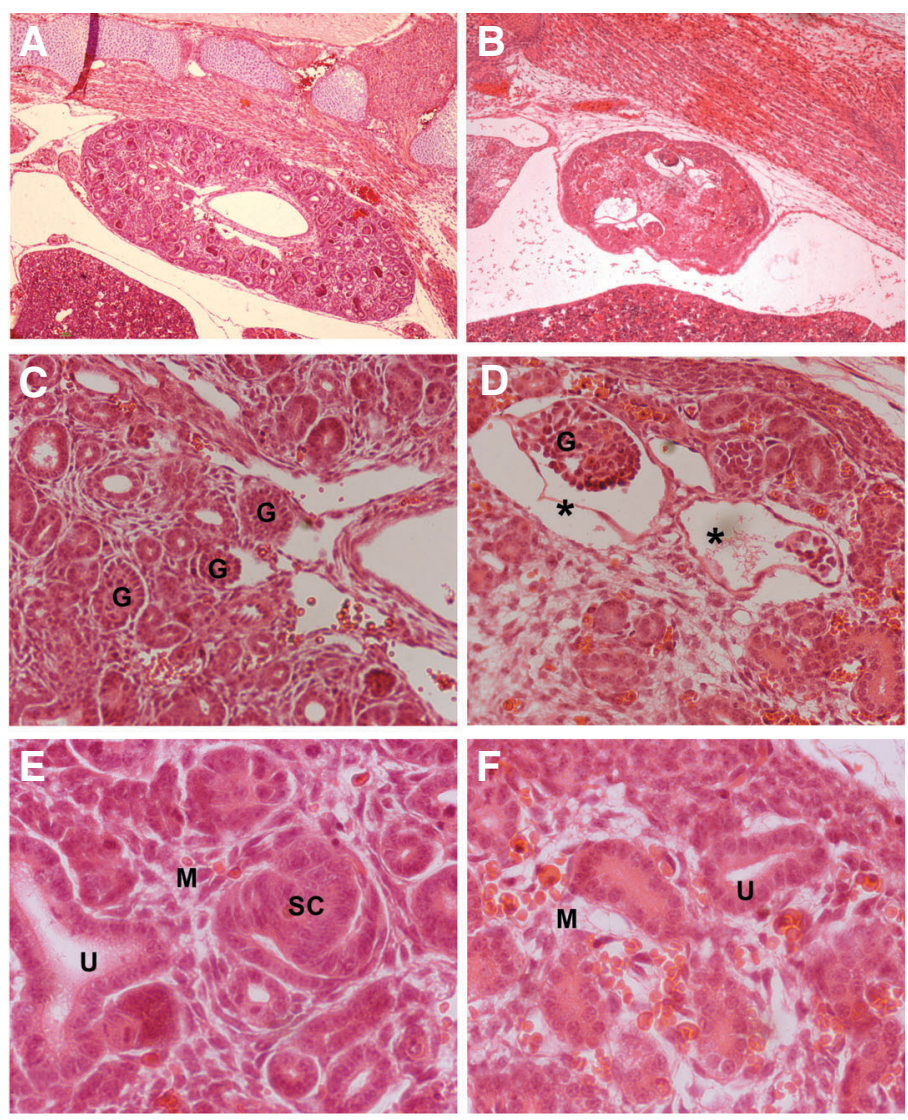

Fig. 6. Kidney phenotype in $\mathbf{B m p} \mathbf{7}^{\Delta \Delta \Delta}$ embryos. Sections of E15.5 embryos stained with Hematoxylin/ Eosin. (A,C,E) Bmp7 wt/wt, (B,D,F) Bmp7 ${ }^{\Delta / \Delta}$. (A,B) $40 \times$ magnification showing that the kidney of the $B \mathrm{mp}^{\Delta / \Delta}$ is hypoplastic with disrupted architecture and loose interstitial mesenchyme compared with the well developed kidney of the Bmp7wt/wt littermate. (C,D) 200x magnification showing glomeruli with dilated cyst-like Bowman's capsules (*) compared to normal glomerulus developmet in wt. (E,F) 400x magnification showing accumulation of loose interstitial mesenchyme (M) in mutant embryos compared to the wt littermate, where S- or Commashaped bodies (SC), ureteric branching (U) and well-connected mesenchymal cells (M) can be detected. 
the role of $B m p 7$ at later embryonic stages and in the postnatal mouse where it will facilitate studies aimed at elucidating the function of BMP7 in homeostasis, disease and tissue repair.

\section{Materials and Methods}

\section{Construction of the Targeting Vector and generation of $\mathrm{Bmp} 7^{\mathrm{fl} / \mathrm{f} \mid \mathrm{x}}$ Mice}

BAC RP23 345E21, which encompasses the exon-intron region of the Bmp7 locus together with flanks of 60 to $70 \mathrm{~kb}$ on either side, was converted into a targeting vector using bacterial homologous recombination in a three-step process: First, a loxP site was introduced $1.66 \mathrm{~kb}$ upstream of the ATG in exon 1 into a non-conserved region, simultaneously replacing the 61 bp sequence (CCATTTTACCACCCCTGAAA CGCTTGGCTTGTCGCCCACCTTCAGCAAAGCAGGAAGCCTG) with a LoxP_I-Scel_EM7-Zeo_I-Scel cassette. The homology boxes used to recombine in this cassette were approximately $50 \mathrm{bp}$ in length. Detailed primer sequences will be made available upon request; second, the IScel_EM7-Zeo_I-Scel cassette was removed from the modified BAC by restricting with I-Scel, re-ligating, and selecting for modified BACs that had lost the Zeo cassette while retaining the LoxP_I-Scel sequence; and third, a loxP site was inserted $1.89 \mathrm{~kb}$ downstream of the end of exon 1 as part of a flippase recombinase target (FRT)-flanked-phosphoglycerate kinase (PGK)-neomycin phosphotransferase (Neo)-polyA_FRT_LoxP cassette, while simultaneously deleting 72 bp (ATCTGTGAGGCCATCCC GAAGCCAGGCTTAACAAGGCCCTCTCCCTGCGTGAGGGTCAGAGCTTATGGCCT) of non-conserved sequence, to accommodate PCR probes for genotyping by loss of native allele assay (Valenzuela et al., 2003). The homology boxes for the 3' donor were approximately $200 \mathrm{bp}$ in length and were ligated to the (FRT)-flanked-phosphoglycerate kinase (PGK)-neomycin phosphotransferase (Neo)polyA_FRT_LoxP cassette prior to recombination. Detailed primer sequences will be made available upon request. The modified BAC was linearized and directly used to target Bmp7 in an F1 (129SvJ/C57BL/6) hybrid ES cell line as described (Valenzuela et al., 2003). Genotyping of ES cell clones using loss of native allele assay revealed that 3 of 288 clones screened were correctly targeted. One targeted ES cell clone was used to generate male chimeric mice. Chimeras that were complete transmitters of ES-derived sperm were bred to $\mathrm{C} 57 \mathrm{BL} / 6$ females to generate $\mathrm{F} 1$ heterozygous mice, which were genotyped by loss of native allele assay. 33/39 offspring that carried the $B m p 7^{f l}(\mathrm{Neo})$ allele were black. The Neo selection cassette was removed by breeding to a Flp-deleter mouse (Farley et al., 2000) and the recombination was passed germline to yield $B m p{ }^{w t} / f x($ neo-) mice, hereon referred to as $B m p 7^{w t / f I x}$ mice. Mice used in this study were further backcrossed for at least five generations to C57BI6/J.

\section{Analysis of Genomic DNA}

Deletion by the Flp and Cre recombinase was documented by PCR on genomic DNA from various tissues using a four primer stratey:

D151: (5'- AAGCCAGCCTCGCTGATTG -3'),

D152 (5'- GCGTGAGGGTCAGAGCTTATG -3'),

D154 (5'- GGTCAGCATGGCCTAGGAAG -3'), and

D155 (5'- TTTAGCCCCTCAGACAGTCAC -3') resulting in products of 407bp (wt allele), 491bp (flx allele) and 607bp ( $\Delta$ allele), or by Southern blot using the D151/D152 PCR product as probe on genomic DNA from ES cells or various tissues digested with either Avrll (to detect wt, $\mathrm{fl}^{(\mathrm{neo+})}$, and $\Delta$ alleles, where $\Delta$ represents the Cre-recombined flx allele) or Xbal (to detect $w t, f \mid x$, and $\Delta$ alleles). To detect the $f\left(x^{(n e+)}\right.$ the additional primer D153 (5'-CATTTGTCACGTCCTGCACGAC-3') was used.

\section{RT-PCR}

For RNA isolation embryos or embryonic tissues were extracted with Trizol (Invitrogen) according to manufacturer's instructions. RNA was quantitated, and $2 \mu \mathrm{g}$ total RNA were used for reverse transcription using oligo dT and M-MLV Reverse Transcritpase (Promega) according to manufacturer's instructions. For PCR, cDNA corresponding to $100 \mathrm{ng}$ RNA was amplified for 33 cycles at $64^{\circ} \mathrm{C}$ for BMP7 or 31 cycles at $60^{\circ} \mathrm{C}$ for GAPDH using the following oligos:

Bmp7F: 5'-AGGAGGGCTGGTTGGTGT-3',

Bmp7R: 5'-GGTGGCGTTCATGTAGGAGT-3',

GAPDHF: 5'-TCTTCTTGTGCAGTGCC-3',

GAPDHR: 5'-ACTCCACGACATACTCAGC-3'. PCR products were analyzed on a $2 \%$ TBE-agarose gel.

\section{Skeletal Preparations}

For skeletal preparations, e14.5-e16.5 embryos were fixed for $2 \mathrm{hrs}$ in $95 \% \mathrm{EtOH}$, eviscerated and fixed for an additional 5 days. The embryos were placed in acetone for at least 2 days. Staining was performed with Alcian Blue (1 vol $0.3 \%$ Alcian Blue $8 \mathrm{GS}$ in $70 \% \mathrm{EtOH} / 1$ vol Glacial Acetic Acid/ 18 vol 70\% EtOH) for 3 days. Embryos were cleared in $1 \% \mathrm{KOH}$, passed to glycerol and photographed on a Leica M9.5 stereoscope equipped with a Leica DFC290 camera.

\section{Histology and Immunohistochemistry}

Embryos obtained from timed matings were embedded in paraffin. Histological analysis was performed on H/E stained sections. Loss of BMP7 protein expression was confirmed by immunohistochemistry for BMP7 using an anti-BMP7 antibody (Santa Cruz). Animal experiments were approved by the Animal Care and Use Committee of the BSRC 'AI. Fleming'.

\section{Acknowledgements}

Many thanks to Maria Alexiou for ES cell work and Motoko Yanagita for discussions and carefully reading the manuscript. This work was supported by grants to DG from AICR, The Greek Ministry of Development, HFSP, and MUGEN NoE 6FP (LSHG-CT-2005-005203)

\section{References}

ADAMS, D., KAROLAK, M., ROBERTSON, E. and OXBURGH, L. (2007). Control of kidney, eye and limb expression of Bmp7 by an enhancer element highly conserved between species. Dev Biol 311: 679-690.

ARA, J., SEE, J., MAMONTOV, P., HAHN, A., BANNERMAN, P., PLEASURE, D. and GRINSPAN, J.B. (2008). Bone morphogenetic proteins 4, 6, and 7 are upregulated in mouse spinal cord during experimental autoimmune encephalomyelitis. J Neurosci Res 86: 125-135.

DE BOER, J., WILLIAMS, A., SKAVDIS, G., HARKER, N., COLES, M., TOLAINI, M., NORTON, T., WILLIAMS, K., RODERICK, K., POTOCNIK, A.J. et al. (2003). Transgenic mice with hematopoietic and lymphoid specific expression of Cre. Eur J Immunol 33: 314-325.

DUDLEY, A.T., LYONS, K.M. and ROBERTSON, E.J. (1995). A requirement for bone morphogenetic protein-7 during development of the mammalian kidney and eye. Genes Dev 9: 2795-2807.

FARLEY, F.W., SORIANO, P., STEFFEN, L.S. and DYMECKI, S.M. (2000). Widespread recombinase expression using FLPeR (flipper) mice. Genesis 28: 106-110.

GODIN, R.E., TAKAESU, N.T., ROBERTSON, E.J. and DUDLEY, A.T. (1998). Regulation of BMP7 expression during kidney development. Development 125: 3473-3482.

GRAF, D., NETHISINGHE, S., PALMER, D.B., FISHER, A.G. and MERKENSCHLAGER, M. (2002). The developmentally regulated expression of Twisted gastrulation reveals a role for bone morphogenetic proteins in the control of T cell development. J Exp Med 196: 163-171.

JENA, N., MARTIN-SEISDEDOS, C., MCCUE, P. and CROCE, C.M. (1997). BMP7 null mutation in mice: developmental defects in skeleton, kidney, and eye. Exp Cell Res 230: 28-37.

JONES, W.K., RICHMOND, E.A., WHITE, K., SASAK, H., KUSMIK, W., SMART, J., OPPERMANN, H., RUEGER, D.C. and TUCKER, R.F. (1994). Osteogenic protein-1 (OP-1) expression and processing in Chinese hamster ovary cells: 
isolation of a soluble complex containing the mature and pro-domains of OP-1. Growth Factors 11: 215-225.

LORIES, R.J. and LUYTEN, F.P. (2005). Bone morphogenetic protein signaling in joint homeostasis and disease. Cytokine Growth Factor Rev 16: 287-298.

LUO, G., HOFMANN, C., BRONCKERS, A.L., SOHOCKI, M., BRADLEY, A. and KARSENTY, G. (1995). BMP-7 is an inducer of nephrogenesis, and is also required for eye development and skeletal patterning. Genes Dev 9: 2808-2820.

MUYRERS, J.P., ZHANG, Y., TESTA, G. and STEWART, A.F. (1999). Rapid modification of bacterial artificial chromosomes by ET-recombination. Nucleic Acids Res 27: 1555-1557.

OZKAYNAK, E., SCHNEGELSBERG, P.N., JIN, D.F., CLIFFORD, G.M., WARREN, F.D., DRIER, E.A. and OPPERMANN, H. (1992). Osteogenic protein-2. A new member of the transforming growth factor-beta superfamily expressed early in embryogenesis. J Biol Chem 267: 25220-25227.

PATEL, S.R. and DRESSLER, G.R. (2005). BMP7 signaling in renal development and disease. Trends Mol Med 11: 512-518.

SANCHO, E., BATLLE, E. and CLEVERS, H. (2004). Signaling pathways in intestinal development and cancer. Annu Rev Cell Dev Biol 20: 695-723.

SCHWENK, F., BARON, U. and RAJEWSKY, K. (1995). A cre-transgenic mouse strain for the ubiquitous deletion of loxP-flanked gene segments including deletion in germ cells. Nucleic Acids Res 23: 5080-5081.

SIMIC, P. and VUKICEVIC, S. (2005). Bone morphogenetic proteins in development and homeostasis of kidney. Cytokine Growth Factor Rev 16: 299-308.

VALENZUELA, D.M., MURPHY, A.J., FRENDEWEY, D., GALE, N.W., ECONOMIDES, A.N., AUERBACH, W., POUEYMIROU, W.T., ADAMS, N.C., ROJAS, J., YASENCHAK, J. et al. (2003). High-throughput engineering of the mouse genome coupled with high-resolution expression analysis. Nat Biotechnol 21: 652-659.

ZEISBERG, M., YANG, C., MARTINO, M., DUNCAN, M.B., RIEDER, F., TANJORE, H. and KALLURI, R. (2007). Fibroblasts derive from hepatocytes in liver fibrosis via epithelial to mesenchymal transition. J Biol Chem 282: 23337-23347.

ZOUVELOU, V., LUDER, H.U., MITSIADIS, T. and GRAF, D. (2009). Deletion of BMP7 affects the development of bones, teeth, and other ectodermal appendages of the orofacial complex J Exp Zoolog B Mol Dev Evol (in press).

\section{Further Related Reading, published previously in the Int. J. Dev. Biol.}

See our recent Special Issue Fertilization, in honor of David L. Garbers and edited by Paul M. Wassarman and Victor D. Vacquier at: http://www.ijdb.ehu.es/web/contents.php?vol=52\&issue=5-6

Expression of Id2 in the developing limb is associated with zones of active BMP signaling and marks the regions of growth and differentiation of the developing digits

Carlos I. Lorda-Diez, Nuria Torre-Pérez, Juan A. García-Porrero, Juan M. Hurle and Juan A. Montero

Int. J. Dev. Biol. (2008) 53: doi: 10.1387/ijdb.072415cl

Expression of Bmp ligands and receptors in the developing Xenopus retina Jennifer C. Hocking and Sarah McFarlane

Int. J. Dev. Biol. (2007) 51: 161-165

Pathways regulating lens induction in the mouse

Richard A. Lang

Int. J. Dev. Biol. (2004) 48: 783-791

BMPs and BMP receptors in mouse metanephric development: in vivo and in vitro studies.

Gemma Martinez, Yuji Mishina and John F Bertram

Int. J. Dev. Biol. (2002) 46: 525-533

Bone morphogenetic proteins, tissue and regeneration

A.H. Reddi

Int. J. Dev. Biol. (2001) 45: S31-S31

Role of BMP family members during kidney development.

R E Godin, E J Robertson and A T Dudley

Int. J. Dev. Biol. (1999) 43: 405-411

2006 ISI **Impact Factor $=3.577^{* *}$

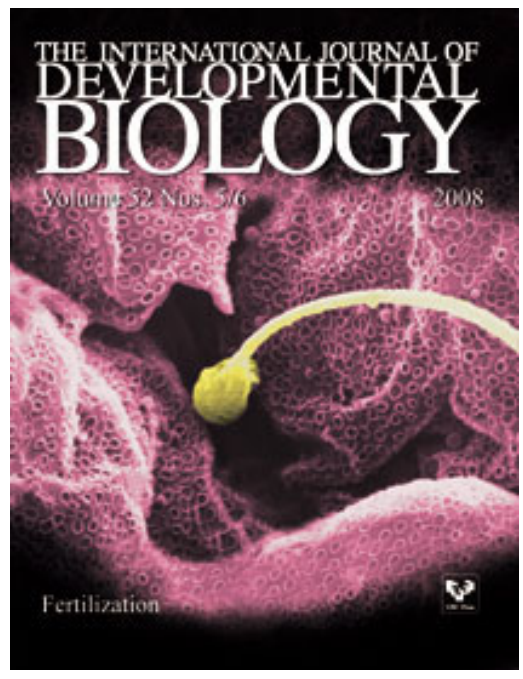

